\title{
Pro- and anti-inflammatory factors, vascular stiffness and outcomes in chronic hemodialysis patients
}

\author{
B. SÁGI ${ }^{1,2}$, A. PETI ${ }^{3}$, O. LAKATOS ${ }^{4}$, T. GYIMESI ${ }^{2}$, E. SULYOK ${ }^{5}$, \\ I. WITTMANN ${ }^{2}$ and BOTOND CSIKY ${ }^{1,2 *}$ (1)
}

\footnotetext{
${ }^{1}$ FMC Dialysis Center Pécs, Pécs, Hungary

2 2nd Department of Medicine and Nephrology-Diabetes Center, Faculty of Medicine, University of Pécs, Pécs, Hungary

${ }^{3}$ Department of Laboratory Medicine, Siófok Hospital, Siófok, Hungary

${ }^{4}$ Department of Pediatrics, Faculty of Medicine, University of Pécs, Pécs, Hungary

${ }^{5}$ Doctoral School of Health Sciences, University of Pécs, Pécs, Hungary
}

Received: August 30, 2019 • Accepted: March 12, 2020

Published online: July 02, 2020

(c) 2020 The Author(s)

\begin{abstract}
Objective: In this observational study we addressed accelerated arteriosclerosis (AS) in patients with chronic renal failure (CRF) on hemodialysis (HD) by measuring vascular stiffness (VS) parameters and attempted to relate them to pro-inflammatory and protective factors. Patients: 96 consecutive patients receiving regular HD were included. 20 adult patients without major renal, cardiovascular or metabolic morbidities served as controls. Methods: AS parameters (carotid-femoral pulse wave velocity - PWV, aortic augmentation index - Aix) were measured by using applanation tonometry (SphygmoCor, AtCor Medical, Sidney). In addition to routine laboratory tests $25(\mathrm{OH})$ vitamin $\mathrm{D}_{3}$ (vitamin $\mathrm{D}_{3}$ ) and high-sensitivity Creactive protein (hsCRP) were quantified by immunometric assay; whereas fetuin-A, $\alpha$-Klotho, tumor necrosis factor- $\alpha$ (TNF- $\alpha$ ) and transforming growth factor- $\beta 1$ (TGF- $\left.\beta_{1}\right)$ were determined by ELISA. Results: Pro-inflammatory biomarkers (hsCRP, TNF- $\alpha$ and TGF- $\left.\beta_{1}\right)$ were markedly elevated $(P<0.01)$, while anti-inflammatory factors (fetuin-A: $P<0.05, \alpha$-Klotho: $P<0.01$, vitamin $\mathrm{D}_{3}: P<0.01$ ) significantly depressed in HD patients when compared to controls. PWV was significantly affected only by total
\end{abstract}

\footnotetext{
* Corresponding author. 2nd Department of Medicine and Nephrology-Diabetes Center, Faculty of Medicine, University of Pécs, Pacsirta u.1., 7624, Pécs, Hungary. Tel.: +36 204743639; Fax: +36 72536070, E-mail: botond. csiky@gmail.com
} 
cholesterol, fetuin-A and dialysis time. Multiple linear regression analyses revealed that several clinical and laboratory parameters were associated with pro- and anti-inflammatory biomarkers rather than VS. The impact of baseline clinical and biochemical variables on outcome measures were also analyzed after threeyear follow-up, and it was demonstrated that low levels of vitamin $\mathrm{D}, \alpha$-Klotho protein and fetuin-A were related to adverse cardiovascular outcomes, whereas all-cause mortality was associated with elevated hsCRP and depressed vitamin D. Conclusions: Our results provide additional information on the pathomechanism of accelerated AS in patients with CRF, and documented direct influence of pro- and anti-inflammatory biomarkers on major outcome measures.

\section{KEYWORDS}

chronic renal failure, hemodialysis, arterial stiffness, inflammation, follow-up

\section{INTRODUCTION}

The concept of accelerated arteriosclerosis (AS) has been well-established in patients with chronic renal failure $(\mathrm{CRF})$ with much higher incidence of cardiovascular complications observed in these patients than those in the general population even after adjustment for traditional cardiovascular risk factors $[1,2]$.

Although the underlying mechanism of the initiation and progression of cardiovascular diseases has not been clearly defined, the contribution of non-traditional risk factors including low-grade inflammation [3], oxidative stress, endothelial dysfunction, advanced glycation endproducts and dysregulated mineral metabolism has been documented [4].

Experimental and clinical evidences indicate that vascular calcification (VC) plays an essential role in the development of cardiovascular diseases in CRF patients. VC is an active, cell-mediated process that includes vascular smooth muscle cells (VSMC) and endothelial cells $[5,6]$. The interaction between endothelium and VSMCs regulates the progression of VC.

The involvement of endothelium in VC is supported by the findings that endothelin and vascular endothelial growth factor accelerate, whereas nitrogen oxide attenuates calcification [7].

Vascular stiffness (VS) is a clinical marker of arteriosclerotic damage and an independent predictor of fatal and non-fatal cardiovascular events in the general population, in elderly subjects and in patients with hypertension, diabetes mellitus and end-stage renal diseases (ESRD) [8].

The present study was undertaken to assess the extent and severity of arteriosclerotic lesion in CRF patients receiving regular hemodialysis (HD). Attempts were also made to relate VS parameters to pro-inflammatory markers (high-sensitivity C-reactive protein (hsCRP), tumor necrosis factor- $\alpha$ (TNF- $\alpha$ ), transforming growth factor- $\beta 1$ (TGF- $\beta 1$ )) and to well-established protective factors $\left(\alpha\right.$-Klotho protein, fetuin-A, vitamin $\mathrm{D}_{3}$ ) to reveal their contribution to the cardiovascular compromise. After baseline evaluation all patients were followed up for three years to analyze the association between outcome measures (cardiovascular events/mortality, allcause mortality) and clinical/biochemical variables. 


\section{PATIENTS AND METHODS}

\section{Patients}

96 (49 male, 47 female) consecutive chronic HD patients in stable clinical condition treated in 2 dialysis centers were enrolled in this observational study. Patients having lower extremity amputation, any acute infection, malignancy, acute myocardial infarction, pulmonary edema or hemodynamic instability were excluded from the study.

The underlying renal pathologies that progressed to ESRD were the following: diabetic nephropathy (24\%), benign nephrosclerosis (26\%), chronic glomerulonephritis (14\%), polycystic kidney disease (16\%), chronic interstitial nephritis (8\%), renovascular disease (1\%) and other/ unknown causes (11\%). Most of the patients (84) received antihypertensive therapy.

The patients underwent 3 HD sessions per week, each having a duration of 4 hours. On-line hemodiafiltration was carried out by using Fresenius $5008 \mathrm{~B}$ equipment with Helixone/Fresenius polysulfone high-flux dialyzer membranes.

20 adult patients without major renal, cardiovascular or metabolic morbidities served as control for the analysis of biochemical parameters. Results presented are predialysis values. Body mass index (BMI) was calculated.

\section{Blood pressure and pulse wave velocity (PWV) measurements}

Blood pressure was measured using calibrated automated devices with appropriate cuff sizes. The results presented here are predialysis values. Pulse pressure and mean arterial pressure were calculated.

Carotid-femoral pulse wave velocity (cfPWV) and augmentation index (Alx) were measured using applanation tonometry (SphygmoCor system, AtCor Medical Australia). Measurements were performed before $\mathrm{HD}$ sessions in supine position after an at least 10-min rest in a quiet, temperature-controlled room. Pulse wave recordings were performed consecutively at two superficial artery sites (carotid-femoral segment). The cfPWV was calculated.

\section{Laboratory measurements}

Routine bichemical parameters were measured by standard methods (Table 1). The serum concentrations of fetuin-A, $\alpha$-Klotho, TNF- $\alpha$, TGF- $\beta 1$ were measured by sandwich enzyme immunoassays (ELISA) (IBL International Gmbh, Hamburg, Germany and BioVendol Laboratory Med. Inc Brno, Czech Republic). The respective intraassay CVs ranged from 4.8 to 5.5\%, $2.7-3.5 \%, 2.0-14.9 \%$, and $1 \%$ (mean), whereas the interassay CVs ranged from 5.7 to $6.8 \%$, 2.9$11.4 \%, 4.1-14.0 \%$, and $7.5 \%$ (mean). hsCRP and vitamin $\mathrm{D}_{3}$ were determined by immunometric assay.

\section{Statistical analysis}

Statistical analyses were performed using SPSS 21.0 software (SPSS, Inc., Chicago, IL, USA). Normality of distribution of data was tested by Kolmogorov-Smirnov test. Non-normally distributed parameters were transformed logarithmically. Correlations between continuous variables were assessed by linear regression using Pearson's test. Comparison of clinical and laboratory parameters was made by Student $t$-test and ANOVA, as appropriate. Data were 
Table 1. Clinical and laboratory characteristics of the 96 chronic hemodialysis patients

\begin{tabular}{lccc}
\hline Anthropometric data & \multicolumn{3}{c}{ Biochemical data } \\
\hline Age (years) & $65.06 \pm 14.09$ & Creatinine $(\mu \mathrm{mol} / \mathrm{l})$ & $683.84 \pm 209.61$ \\
Height $(\mathrm{cm})$ & $162.97 \pm 12.04$ & BUN $(\mathrm{mmol} / \mathrm{l})$ & $19.47 \pm 5.31$ \\
Body weight $(\mathrm{kg})$ & $72.21 \pm 17.87$ & spKt/V & $1.64 \pm 0.34$ \\
Body mass index $\left(\mathrm{kg} / \mathrm{m}^{2}\right)$ & $26.78 \pm 6.03$ & Hemoglobin $(\mathrm{g} / \mathrm{l})$ & $115.52 \pm 12.94$ \\
Dialysis vintage (months) & $54.48 \pm 42.26$ & Albumin $(\mathrm{g} / \mathrm{l})$ & $40.38 \pm 5.58$ \\
SBP $(\mathrm{mmHg})$ & $140.21 \pm 18.36$ & Total cholesterol $(\mathrm{mmol} / \mathrm{l})$ & $4.69 \pm 1.24$ \\
DBP (mmHg) & $80.32 \pm 9.87$ & LDL cholesterol $(\mathrm{mmol} / \mathrm{l})$ & $2.95 \pm 1.04$ \\
Pulse pressure $(\mathrm{mmHg})$ & $62.58 \pm 18.37$ & HDL cholesterol $(\mathrm{mmol} / \mathrm{l})$ & $1.08 \pm 0.34$ \\
MAP (mmHg) & $96.6 \pm 11.84$ & Triglyceride $(\mathrm{mmol} / \mathrm{l})$ & $1.55 \pm 1.23$ \\
AIx & $29.85 \pm 10.33$ & Sodium $(\mathrm{mmol} / \mathrm{l})$ & $139.53 \pm 2.26$ \\
PWV (m/s) & $8.31 \pm 2.38$ & Potassium $(\mathrm{mmol} / \mathrm{l})$ & $4.9 \pm 0.63$ \\
Central SBP (mmHg) & $123.61 \pm 18.30$ & Calcium $(\mathrm{mmol} / \mathrm{l})$ & $2.29 \pm 0.34$ \\
Central DBP (mmHg) & $80.21 \pm 8.79$ & Phosphate $(\mathrm{mmol} / \mathrm{l})$ & $1.65 \pm 0.49$ \\
Central pulse pressure $(\mathrm{mmHg})$ & $47.74 \pm 15.27$ & Alkaline phosphatase $(\mathrm{IU} / \mathrm{l})$ & $100.8 \pm 44.04$ \\
& & iPTH (pmol/l) & $29.96 \pm 16.12$ \\
\hline
\end{tabular}

SBP, systolic blood pressure; DBP, diastolic blood pressure; MAP, mean arterial pressure; PWV, carotidfemoral pulse wave velocity; BUN, blood urea nitrogen; spKt/v, single pool Kt/V; LDL cholesterol, lowdensity lipoprotein cholesterol; HDL cholesterol, high-density lipoporotein cholesterol; iPTH, intact parathyroid hormone.

expressed as mean \pm SD in case of normal distribution, and median (lower/upper quartile) in case of non-normal distribution. Backward multiple regression analyses were performed to determine the relative contribution of selected independent variables in the constructed models to the variance of the dependent variable. Values of $P<0.05$ were considered statistically significant.

\section{Ethical considerations}

The research was approved by the Regional Ethical Committee. The investigation conforms to the principles outlined in the World Medical Association Declaration of Helsinki. Informed written consent was obtained from all participants.

\section{RESULTS}

Pro-inflammatory (pro-calcigenic) biomarkers (hsCRP, TNF- $\alpha$, TGF- $\beta 1$ ) were markedly elevated $(P<0.01)$, whereas anti-inflammatory (anti-atherosclerotic) factors (fetuin-A: $P<0.05$, $\alpha$-Klotho: $P<0.01$, vitamin $\left.\mathrm{D}_{3} P<0.01\right)$ significantly depressed when compared to healthy adults (Table 2).

Univariate linear regression analyses carried out to reveal the association of AS with the clinical and laboratory parameters have shown that cfPWV correlated positively with Alx ( $r=$ 0.237, $P<0.05)$, total cholesterol $(r=0.244, P<0.05)$ and fetuin-A $(r=0.282, P<0.05)$ but inversely with the time spent on $\mathrm{HD}(r=-0.262, P<0.05)$. cfPWV appeared to be independent of all other variables studied (Table 3 ). 
Table 2. Plasma levels of pro- and anti-inflammatory and calcigenic factors in end-stage renal failure patients receiving chronic hemodialysis

\begin{tabular}{lcccccc}
\hline & $\begin{array}{c}\text { Vitamin D3 } \\
(\mathrm{nmol} / \mathrm{l})\end{array}$ & $\begin{array}{c}\text { Fetuin A } \\
(\mathrm{g} / \mathrm{l})\end{array}$ & $\begin{array}{c}\alpha \text {-Klotho } \\
(\mathrm{pg} / \mathrm{mL})\end{array}$ & $\begin{array}{c}\text { TNF- } \alpha \\
(\mathrm{pg} / \mathrm{mL})\end{array}$ & $\begin{array}{c}\text { TGF } \beta-1 \\
(\mathrm{ng} / \mathrm{mL})\end{array}$ & $\begin{array}{c}\text { hsCRP } \\
(\mathrm{mg} / \mathrm{l})\end{array}$ \\
\hline Patients & $11.4 \pm 7.5$ & $0.43 \pm 0.11$ & $299.3 \pm 124.7$ & $20.2 \pm 15.9$ & $2.85 \pm 1.35$ & $11.8 \pm 10.4$ \\
Controls & $52.2 \pm 13.1$ & $0.55 \pm 0.09$ & $602 \pm 100$ & $5.2 \pm 1.3$ & $0.69 \pm 0.42$ & $4.51 \pm 5.31$ \\
$P$ & 0.001 & 0.05 & 0.01 & 0.01 & 0.00 & 0.01 \\
\hline
\end{tabular}

TNF- $\alpha$ : tumor necrosis factor- $\alpha$, TGF $\beta$-1: transforming growth factor $\beta-1$, hsCRP: high-sensitivity Creactive protein.

${ }^{*} P<0.05$ is considered statistically significant.

Further analysis to explore the contribution of various clinical and laboratory factors to the variance of VS parameters was made by applying multiple regression models. These included Alx as a dependent variable, and cfPWV, central augmentation pressure, central systolic blood pressure, central pulse pressure, $\mathrm{Kt} / \mathrm{V}$ and parathyroid hormone as independent varibles. Only central augmentation pressure $(\beta=1.318, P<0.000)$ and central pulse pressure $(\beta=-0.71, P<$ 0.00 ) had significant contribution. cfPWV as dependent variable was significantly affected by fetuin-A $(\beta=0.24, P<0.03)$ and dialysis time $(\beta=-0.23, P<0.04)$.

Multiple linear regression models were also applied to establish independent variables that have significant impact on the pro- and anti-inflammatory biomarkers studied. Out of the proinflammatory markers, the variance of hsCRP was negatively influenced by plasma vitamin $\mathrm{D}_{3}$ $(\beta=-0.23, P<0.01)$, sodium $(\beta=-0.26, P<0.00)$ and albumin levels $(\beta=-0.36, P<0.00)$ and positively by BMI $(\beta=0.76, P<0.00)$. TNF $\alpha$ and TGF- $\beta 1$ as dependent variables were found to correlate significantly only with $\alpha$-Klotho $(\beta=0.41, P<0.00)$ and plasma creatinine $(\beta=0.30, P<0.003)$, as well as with fetuin-A $(\beta=-0.24, P<0.02)$ and plasma albumin $(\beta=0.33, P<0.002)$, respectively.

Analysis of protective factors by applying this multiple regression model revealed significant negative association of fetuin-A with age $(\beta=-0.225, P<0.05)$, TGF- $\beta 1(\beta=-0.228, P<$ $0.02)$, and dialysis time $(\beta=-0.26, P<0.01)$, whereas a positive relationship was found between fetuin-A and triglyceride levels $(\beta=0.43, P<0.00)$. $\alpha$-Klotho as dependent variable correlated positively with TNF- $\alpha(\beta=0.44, P<0.00)$ and negatively with plasma calcium $(\beta=$ $-0.24, P<0.01)$.

During the follow-up period of three years 25 patients $(26.6 \%)$ encountered cardiovascular events that requited hospital admission. 11 patients $(11.7 \%)$ died due to cardiovascular pathologies and the all-cause mortality accounted to 31 patients (33.0\%).

Patients with cardiovascular events were older and had significantly depressed serum levels of vitamin D, $\alpha$-Klotho protein and fetuin-A than those without these pathologies. Cardiovascular parameters, inflammatory markers and routine laboratory tests proved to be similar in the two groups. Essentially the same results were seen when patients with and without cardiovascular death were compared. All-cause mortality was also associated with older age and markedly reduced vitamin D levels, but they had elevated hsCRP. These findings strongly suggest that vitamin $\mathrm{D}$ depletion and inflammation may play a major role in adverse cardiovascular outcomes in uremic patients on HD (Table 4). 
Table 3. Correlation of carotid-femoral pulse wave velocity and clinical-laboratory variables using univariable linear regression analysis among 96 chronic hemodialysis patients

\begin{tabular}{|c|c|c|}
\hline Variable & $R$ value & $P$ value \\
\hline Age (years) & -0.214 & 0.058 \\
\hline Dialysis time (months) & $-0.262^{*}$ & 0.019 \\
\hline Height $(\mathrm{cm})$ & 0.060 & 0.600 \\
\hline Body weight (kg) & $0.230^{*}$ & 0.042 \\
\hline BMI $\left(\mathrm{kg} / \mathrm{m}^{2}\right)$ & 0.196 & 0.084 \\
\hline Vitamin D (nmol/l) & 0.203 & 0.073 \\
\hline iPTH (pmol/l) & 0.012 & 0.919 \\
\hline Fetuin A $(\mathrm{g} / \mathrm{l})$ & $0.282^{*}$ & 0.012 \\
\hline$\alpha$-Klotho $(\mathrm{pg} / \mathrm{ml})$ & 0.016 & 0.886 \\
\hline TNF- $\alpha(\mathrm{pg} / \mathrm{ml})$ & -0.177 & 0.163 \\
\hline TGF $\beta-1(\mathrm{ng} / \mathrm{ml})$ & -0.093 & 0.456 \\
\hline Augmentation index & $0.237^{*}$ & 0.035 \\
\hline Central augmentation pressure $(\mathrm{mmHg})$ & $0.247^{*}$ & 0.028 \\
\hline Central SBP (mmHg) & 0.157 & 0.167 \\
\hline Central DBP (mmHg) & -0.004 & 0.973 \\
\hline Central pulse pressure (mmHg) & 0.210 & 0.065 \\
\hline $\mathrm{SBP}(\mathrm{mmHg})$ & 0.111 & 0.331 \\
\hline $\mathrm{DBP}(\mathrm{mmHg})$ & 0.006 & 0.957 \\
\hline Pulse pressure (mmHg) & 0.128 & 0.261 \\
\hline MAP (mmHg) & 0.155 & 0.172 \\
\hline hsCRP (mg/l) & -0.015 & 0.900 \\
\hline Creatinine $(\mu \mathrm{mol} / \mathrm{l})$ & -0.066 & 0.565 \\
\hline BUN (mmol/l) & -0.041 & 0.717 \\
\hline $\mathrm{spKt} / \mathrm{V}$ & -0.075 & 0.509 \\
\hline Hemoglobin $(\mathrm{g} / \mathrm{l})$ & 0.109 & 0.341 \\
\hline Calcium (mmol/l) & -0.042 & 0.714 \\
\hline Phosphate $(\mathrm{mmol} / \mathrm{l})$ & -0.159 & 0.161 \\
\hline Alkaline phosphatase (IU/l) & -0.074 & 0.520 \\
\hline Sodium $(\mathrm{mmol} / \mathrm{l})$ & 0.083 & 0.465 \\
\hline Potassium $(\mathrm{mmol} / \mathrm{l})$ & -0.095 & 0.405 \\
\hline Total cholesterol (mmol/l) & $0.244^{*}$ & 0.037 \\
\hline LDL cholesterol (mmol/l) & 0.049 & 0.680 \\
\hline HDL cholesterol (mmol/l) & -0.139 & 0.245 \\
\hline Triglyceride (mmol/l) & 0.141 & 0.235 \\
\hline Albumin $(g / l)$ & 0.083 & 0.471 \\
\hline
\end{tabular}

BMI, body mass index; SBP systolic blood pressure; DBP, diastolic blood pressure; BUN, blood urea nitrogen; LDL-cholesterol, low-density lipoporotein cholesterol; HDL-cholesterol, high-density lipoprotein cholesterol; iPTH, intact parathyroid hormone.

${ }^{*} P<0.05$ is considered statistically significant. 
Table 4. Outcome measures of cardivascular events, cardiovascular mortality and all-cause mortality in hemodialysis patients

\begin{tabular}{|c|c|c|c|c|c|c|}
\hline \multirow[b]{3}{*}{ Select baseline parameters } & \multicolumn{6}{|c|}{ Outcome measures } \\
\hline & \multicolumn{2}{|c|}{ Cardiovascular events } & \multicolumn{2}{|c|}{ Cardiovascular mortality } & \multicolumn{2}{|c|}{ All-cause mortality } \\
\hline & no & yes & no & yes & no & yes \\
\hline$n$ & 69 & 25 & 63 & 11 & 63 & 31 \\
\hline age (years) & $63.09 \pm 14.4^{*}$ & $70.5 \pm 12.1$ & $61.6 \pm 14.5^{* *}$ & $73.4 \pm 8.3$ & $61.6 \pm 14.5^{* * *}$ & $71.9 \pm 10.6$ \\
\hline BMI (kg/m2) & $26.2 \pm 5.3$ & $28.3 \pm 7.3$ & $26.8 \pm 6.1$ & $27.3 \pm 7.9$ & $26.8 \pm 6.1$ & $26.7 \pm 5.6$ \\
\hline augmentation index & $30.01 \pm 9.3$ & $30.6 \pm 12.6$ & $29.6 \pm 10.1$ & $32.2 \pm 13.3$ & $29.6 \pm 10.1$ & $31.2 \pm 10.5$ \\
\hline pulse wave velocity (m/sec) & $7.8(7 ; 9.3)$ & $7.7(6.3 ; 8.7)$ & $7.7(6.6 ; 8.8)$ & $8.6(7.8,9.5)$ & $7.7(6.6 ; 8.8)$ & $8.2(7.2 ; 9.2)$ \\
\hline systolic blood pressure $(\mathrm{mm} / \mathrm{Hg})$ & $140(120 ; 150)$ & $140(120 ; 145)$ & $140(120 ; 150)$ & $120(100 ; 160)$ & $140(120 ; 150)$ & $140(120 ; 150)$ \\
\hline diastolic blood pressure $(\mathrm{mm} / \mathrm{Hg})$ & $80(60 ; 80)$ & $80(60 ; 80)$ & $80(70 ; 80)$ & $80(60,80)$ & $80(70 ; 80)$ & $80(60 ; 80)$ \\
\hline urea nitrogen $(\mathrm{mmol} / \mathrm{l})$ & $20 \pm 5.5$ & $17.8 \pm 3.8$ & $20.4 \pm 5.4^{*}$ & $17.1 \pm 2.6$ & $20.4 \pm 5.4^{* *}$ & $17.6 \pm 4.1$ \\
\hline creatinine $(\mu \mathrm{mol} / \mathrm{l})$ & $695.8 \pm 201.1$ & $650.4 \pm 230.6$ & $713.5 \pm 221.5$ & $635.5 \pm 138.5$ & $713.5 \pm 221.5^{*}$ & $623.2 \pm 168.5$ \\
\hline hemoglobin $(g / l)$ & $11.6(11 ; 12.3)$ & $11.4(10.7 ; 12.3)$ & $11.5(11.1 ; 12.3)$ & $11.2(10.5 ; 11.9)$ & $11.5(11.1 ; 12.3)$ & $11.6(10.6 ; 12.4)$ \\
\hline albumin $(\mathrm{g} / \mathrm{l})$ & $41.8(32.7 ; 43.5)$ & $39.3(38.6 ; 42.2)$ & $42.1(38.7 ; 43.9)$ & $38.9(38 ; 40.1)$ & $42.1(38.7 ; 43.9)$ & $38.9(37.2 ; 41.8)$ \\
\hline parathyreoid hormon (pmol/l) & $29.9(16.1 ; 42.2)$ & $26.9(15.1 ; 66.2)$ & $30.8(17.4 ; 48.2)$ & $20.5(13.4 ; 30.4)$ & $30.8(17.4 ; 48.2)$ & $21.4(13.4 ; 39.2)$ \\
\hline calcium $(\mathrm{mmol} / \mathrm{l})$ & $2.33(2.21 ; 2.43)$ & $2.24(2.18 ; 2.41)$ & $2.36(2.2 ; 2.46)^{* *}$ & $2.19(2.14 ; 2.22)$ & $2.36(2.2 ; 2.46)^{* *}$ & $2.24(2.16 ; 2.28$ \\
\hline phosphate $(\mathrm{mmol} / \mathrm{l})$ & $1.6 \pm 0.4$ & $1.6 \pm 0.5$ & $1.7 \pm 0.7$ & $1.5 \pm 0.5$ & $1.7 \pm 0.5^{*}$ & $1.5 \pm 0.4$ \\
\hline vitamin $\mathrm{D}_{3}(\mathrm{nmol} / \mathrm{l})$ & $15.2(8.3 ; 28.5)^{*}$ & $7.8(7.5 ; 15)$ & $16.7(7.7 ; 29)^{\star *}$ & $7.8(7.5 ; 10.2)$ & $16.7(7.7 ; 29)^{* *}$ & $8.8(7.5,15.2)$ \\
\hline fetuin-A $(\mathrm{g} / \mathrm{l})$ & $0.45 \pm 0.13^{*}$ & $0.39 \pm 0.1$ & $0.45 \pm 0.1^{\star}$ & $0.37 \pm 0.1$ & $0.45 \pm 0.1$ & $0.42 \pm 0.14$ \\
\hline$\alpha$-Klotho protein $(\mathrm{pg} / \mathrm{ml})$ & $314.1 \pm 135.6^{\star}$ & $257.6 \pm 79.5$ & $304.6 \pm 118.9^{*}$ & $227.3 \pm 82.3$ & $304.6 \pm 118.9$ & $287.9 \pm 138.9$ \\
\hline hsCRP (mg/l) & $5.4(1.7 ; 11.2)$ & $6.4(2.1 ; 12.8)$ & $3.6(1.4 ; 10.3)$ & $8.4(3.9 ; 11.3)$ & $3.6(1.4 ; 10.3)^{* *}$ & $8.2(5.2 ; 15)$ \\
\hline $\mathrm{TNF} \alpha(\mathrm{pg} / \mathrm{ml})$ & $21.3(16.2 ; 37.9)$ & $18.8(14.3 ; 38.2)$ & $20.2(15.9 ; 39.9)$ & $18.5(12.8 ; 21.6)$ & $20.2(15.9 ; 39.9)$ & $21.3(14.5 ; 37.4)$ \\
\hline TGF- $\beta 1$ (ng/ml) & $0.65(0.4 ; 1.14)$ & $0.98(0.55 ; 4.16)$ & $0.69(0.42 ; 1.4)$ & $0.74(0.51 ; 3.2)$ & $0.69(0.42 ; 1.4)$ & $0.68(0.42 ; 1.3)$ \\
\hline
\end{tabular}

Significant differences between groups: ${ }^{\star} P<0.05,{ }^{\star \star} P<0.01,{ }^{\star * \star} P<0.001$. 


\section{DISCUSSION}

Our present study confirmed that the pro-inflammatory cascade of AS was activated and inflammatory biomarkers (hsCRP, TNF- $\alpha$, TGF- $\beta 1$ ) prevailed over protective factors (vitamin $\mathrm{D}, \alpha$-Klotho, Fetuin-A) in patients on HD. We demonstrated that cfPWV as a measure of AS was significantly affected by total cholesterol, fetuin-A and dialysis time; all other variables studied had no apparent impact on stiffness parameters. Importantly, several clinical and laboratory factors were associated with pro- and anti-inflammatory biomarkers rather than with AS, underlining the complexity of the relationship between uremic environment, low-grade inflammation and cardiovascular health.

When select baseline parameters were analyzed at the end of the follow-up period of three years, adverse cardiovascular outcomes were found to be associated with significantly decreased vitamin D, $\alpha$-Klotho protein and fetuin-A levels. All-cause mortality was strongly related to vitamin $\mathrm{D}$ depletion and elevated hsCRP.

\section{Inflammation}

The crucial role of inflammation in the initiation and progression of cardiovascular diseases is well established [9]. Expression of pro-inflammatory cytokines has been shown in all cell types involved in the pathogenesis of AS, and they have been claimed to be responsible for the cross-talk among endothelial, smooth muscle cells, leukocytes and other vascular residing cells [10]. Recently a new concept has emerged contending that independent of typical inflammation, inflammasome activation may serve as a basic mechanism to mediate and promote the progression of cardiovascular diseases. Accordingly, inflammasome activation may cause endothelial dysfunction and injury, stimulation of myofibroblast proliferation and differentiation with enhanced synthesis of collagen and other extracellular matrix proteins, as well as it may trigger and amplify the inflammatory response of leukocytes [11].

Patients on HD have pro-inflammatory condition and the severity of inflammation correlates with VS [12]. Compelling evidences have been provided to indicate a singificant association between VS and increased cardiovascular morbidity and mortality in patients with chronic renal disease [13] and in those receiving HD [12]. VS is widely used as a measure of this association and PWV has been shown to be higher in patients on HD than in healthy controls. Moreover, its increase over time in ESRD patients exceeds the age-related increase in the healthy population, indicating that vascular ageing is accelerated by ESRD $[14,15]$.

In our study AC was not assessed directly but an attempt was made to reveal the association of stiffness parameters with markers of inflammation. Surprisingly, both the Alx and cfPWV proved to be independent of pro-inflammatory (hsCRP, TNF- $\alpha$, TGF- $\beta 1$ ) and anti-inflammatory (vitamin $\mathrm{D}$, fetuin-A, $\alpha$-Klotho) biomarkers. However, inflammation per se was significantly influenced by several clinical and laboratory variables of uremia. These include vitamin D deficiency, hyponatraemia, hypoalbuminaemia, plasma creatinine, dialysis time, BMI and age.

\section{Vitamin D}

We paid particular attention to defining the possible role of protective mechanisms that may attenuate the vascular damage. Vitamin D deficiency has emerged as a cardiovascular riskfactor. Beneficial interaction has been described between vitamin D and CRP, interleukins and anti-inflammatory cytokines [16], and it has been demonstrated to improve endothelial function [17] and to inhibit VSMC proliferation [18]. 
In spite of available evidences for cardiovascular protection by vitamin $\mathrm{D}$, metaanalyses of randomized controlled clinical trials expressed concern about the impact of vitamin D deficiency on cardiovascular health. To reconcile the conflicting results the concept has emerged that the association between vitamin D levels and cardiavascular morbidities is U-shaped and there is a therapeutic window that should be considered when vitamin D is administered [19]. Most recently Qi et al. have claimed that biomarkers of vitamin D status beyond $25(\mathrm{OH})$ vitamin D (vitamin D-binding protein and parathyorid hormon) may have an independent and synergistic association with the risk of cardiovascular diseases [20]. In our study population an apparent vitamin $\mathrm{D}$ deficiency was documented that was associated with adverse cardiavascular outcomes and all-cause mortality and was related to inflammation (hsCRP) rather than VS.

\section{$\alpha$-Klotho}

The role of $\alpha$-Klotho protein in the progression of arteriosclerotic processes is also a subject of controversies. It was identified as an anti-ageing factor but was subsequently discovered to have multiple biological actions including cytoprotection mediated by anti-inflammation, antioxidation and anti-apoptosis [21, 22].

It has been reported that the renal expression of Klotho mRNA is markedly reduced in patients with CRF [23], and a low level of circulating $\alpha$-Klotho has been detected in patients on $\mathrm{HD}$, but this has not been associated with cardiovascular diseases [24]. On the other hand, there are studies indicating that soluble Klotho protects against uremic cardiomyopathy [25], and Klotho upregulation ameliorates VC in patients with CRF [26]. With this contention in line haplodeficiency of Klotho gene causes arterial stiffening [27].

Our present study confirmed previous observations of depressed soluble Klotho levels in patients on regular HD, but failed to detect their association with VS. The positive relationship of $\alpha$-Klotho to TNF- $\alpha$ may be regarded as indicating an adaptive elevation of $\alpha$-Klotho to mitigate inflammatory reaction.

\section{Fetuin-A}

Our further purpose was to assess possible vasculo-protection by fetuin-A. Fetuin-A is a multifunctional protein that plays a critical role in a variety of metabolic and vascular diseases including obesity, diabetes mellitus type 2, metabolic syndrome and atherosclerosis [13]. It acts as an antagonist of members of the TGF- $\beta$ superfamilies, suppresses TNF- $\alpha$ release from macrophages and inhibits calcification by forming soluble mineral complexes $[28,29]$.

Inconsistent data have been reported on the involvement of fetuin-A in the development of the vascular pathologies of chronic renal diseases. The inconsistencies are supposed to be due to the biphasic response pattern of plasma fetuin-A during the course of the disease. In advanced stage fetuin-A levels are decreased and inversely related to VS as evaluated by PWV [30]. The low levels may be accounted for by its reduced production and/or its consumption to form fetuin-mineral complex. In the early stage of chronic renal disease fetuin- $\mathrm{A}$ is upregulated to provide protection against pro-inflammatory, pro-calcific stress [31]. In agreement with this notion, in our HD patients fetuin-A correlated positively with PWV.

In view of the conflicting data on the role fetuin-A in ESRD patients on HD, we line up with those who think that using this biomarker in clinical practice is presently unwarranted [32]. 


\section{Study limitations}

Only a limited number of HD patients were included and we did not have enough age-matched control participants, thus the selection bias cannot be excluded. Only a few individual biomarkers were selected and measured. To get further insight into the pathomechanism of vascular damage in ESRD, proteomic and/or metabolomic studies are to be conducted.

\section{ACKNOWLEDGMENT}

The authors do not have any financial support or conflict of interest to declare.

\section{REFERENCES}

1. Go AS, Chertow GM, Fan D, McCulloch CE, Hsu C. Chronic kidney disease and the risk of death, cardiavascular events, and hospitalization. N Engl J Med 2004; 351: 1296-305.

2. Shroff R, Long DA, Shanahan C. Mechanistic insights into vascular calcification in CKD. J Am Soc Nephrol 2013; 24: 179-89.

3. Jain S, Khera R, Corrales-Medina VF, Townsend RR, Chirinos JA. Inflammation and arterial stiffness in humans. Atherosclerosis 2014; 237: 381-90.

4. Shroff RC, Shanahan CM. Vascular calcification in patients with kidney disease: The vascular biology of calcification. Semin Dial 2007; 20: 103-9.

5. Schoppet M, Shroff RC, Hofbauer LC, Shanahan CM. Exploring the biology of vascular calcification in chronic kidney disease: what's circulating? Kidney Int 2008; 73: 384-90.

6. Soriano S, Carmona A, Triviño F, Rodriguez M, Alvarez-Benito M, Martín-Malo A, et al. Endothelial damage and vascular calcification in patients with chronic kidney disease. Am J Physiol Renal Physiol 2014; 307: F1302-11.

7. David S, John SG, Jefferies HJ, Sigrist MK, Kümpers P, Kielstein JT, et al. Angiopoietin-2 levels predict mortality in CKD patients. Nephrol Dial Transplant 2012; 27: 1867-72.

8. Vlachopoulos C, Aznaouridis K, Stefanadis C. Prediction of cardiovascular events and all-cause mortality with arterial stiffness. J Am Coll Cardiol 2010; 55: 1318-27.

9. Lakkur S, Judd S, Bostick RM, McClellan W, Flanders WD, Stevens VL, et al. Oxidative stress, inflammation, and markers of cardiovascular health. Atherosclerosis 2015; 243: 38-43.

10. Tousoulis D, Economou EK, Oikonomou E, Papageorgiou N, Siasos G, Latsios G, et al. The role and predictive value of cytokines in atherosclerosis and coronary artery disease. Curr Med Chem 2015; 22: 2636-50.

11. Li P-L. Cardiovascular pathobiology of inflammasomes: inflammatory machinery and beyond. Antioxid Redox Signal 2015; 22: 1079-83.

12. Gauthier-Bastien A, Ung RV, Larivière R, Mac-Way F, Lebel M, Agharazii M. Vascular remodeling and media calcification increases arterial stiffness in chronic kidney desease. Clin Exp Hypertens 2014; 36: 173-80.

13. Górriz JL, Molina P, Cerverón MJ, Vila R, Bover J, Nieto J, et al. Vascular calcification in patients with nondialysis CKD over 3 years. Clin J Am Soc Nephrol 2015; 10: 654-66.

14. Georgianos PI, Sarafidis PA, Lasaridis AN. Arterial stiffness: a novel cardiovascular risk factor in kidney disease patients. Curr Vasc Pharmacol 2015; 13: 229-38.

15. Othmane TEH, Nemcsik J, Fekete BC, Deák G, Egresits J, Fodor E, et al. Arterial stiffness in hemodialysis: which parameter to measure to predict cardiavascular mortality?. Kidney Blood Press Res 2009; 32: 250-7. 
16. Schnatz PF, Vila-Wright S, Jiang X, Register TC, Kaplan JR, Clarkson TB, et al. The association between plasma $250 \mathrm{HD} 3$ concentrations, C-reactive protein levels, and coronary artery atherosclerosis in postmenopausal monkeys. Menopause 2012; 19: 1074-80.

17. Gurses KM, Tokgozoglu L, Yalcin MU, Kocyigit D, Dural M, Canpinar H, et al. Markers of subclinical atherosclerosis in premenopausal women with vitamin D deficiency and effect of vitamin D replacement. Atherosclerosis 2014; 237: 784-9.

18. Wu-Wong JR, Nakane M, Ma J, Ruan X, Kroeger PE. Effects of vitamin D analogs on gene expression profiling in human coronary artery smooth muscle cells. Atherosclerosis 2006; 186: 20-8.

19. Schnatz PF, Manson JA. Vitamin D and cardiovascular disease: an appraisal of the evidence. Clin Chem 2014; 60: 600-9.

20. Qi L, Ma W, Heianza Y, Zheng Y, Wang T, Sun D, et al. Independent and synergistic associations of biomarkers of vitamin D status with risk of coronary heart disease. Arterioscler Thromb Vasc Biol 2017; 37: 2204-12.

21. Imura A, Iwano A, Tohyama O, Tsuji Y, Nozaki K, Hashimoto N, et al. Secreted Klotho protein in sera and CSF: implication for post-translational cleavage in release of Klotho protein from cell membrane. FEBS Lett 2004; 565: 143-7.

22. Kuro OM. Klotho as a regulator of oxidative stress and senescence. Biol Chem 2008; 389: 233-41.

23. Koh N, Fujimori T, Nishiguchi S, Tamori A, Shiomi S, Nakatani T, et al. Severely reduced production of klotho in human chronic renal failure kidney. Biochem Biophys Res Commun 2001; 280: 1015-20.

24. Buiten MS, de Bie MK, Bouma-de Krijger A, van Dam B, Dekker FW, Jukema JW, et al. Soluble Klotho is not independently associated with cardiovascular disease in a population of dialysis patients. BMC Nephrol 2014; 15: 197.

25. Xie J, Yoon J, An SW, Kuro-o M, Huang CL. Soluble Klotho protects against uremic cardiomyopathy independently of fibroblast growth factor 23 and phosphate. J Am Soc Nephrol 2015; 26: 1150-60.

26. Zhao Y, Zhao MM, Cai Y, Zheng MF, Sun WL, Zhang SY, et al. Mammalian target of rapamycin signaling inhibition ameliorates vascular calcification via Klotho upregulation. Kidney Int 2015; 88: 711-21.

27. Chen K, Zhou X, Sun Z. Haplodeficiency of Klotho gene causes arterial stiffening via upregulation of scleraxis expression and induction of autophagy. Hypertension 2015; 66: 1006-13.

28. Komaba H, Fukagawa M. Fetuin-mineral complex: a new potential biomarker for vascular calcification? Kidney Int 2009; 75: 874-6.

29. Mori K, Emoto M, Inaba M. Fetuin-A: A multifunctional protein. Recent Pat Endocr Metab Immune Drug Disc 2011; 5: 124-46.

30. Ford ML, Tomlinson LA, Smith ER, Rajkumar C, Holt SG. Fetuin-A is an independent determinant of change of aortic stiffness over 1 year in non-diabetic patients with CKD stages 3 and 4. Nephrol Dial Transplant 2010; 25: 1853-8.

31. Shroff RC, Shah V, Hiorns MP, Schoppet M, Hofbauer LC, Hawa G, et al. The circulating calcification inhibitors, fetuin-A and osteoprotegerin, but not Matrix Gla protein, are associated with vascular stiffness and calcification in children on dialysis. Neprol Dial Transplant 2008; 23: 3263-71.

32. Liabeuf S, Okazaki H, Desjardins L, Fliser D, Goldsmith D, Covic A, et al. Vascular calcification in chronic kidney disease: are biomarkers useful for probing the pathobiology and the health risks of this process in the clinical scenario? Nephrol Dial Transplant 2014; 29: 1275-84.

Open Access statement. This is an open-access article distributed under the terms of the Creative Commons Attribution 4.0 International License (https://creativecommons.org/licenses/by/4.0/), which permits unrestricted use, distribution, and reproduction in any medium, provided the original author and source are credited, a link to the CC License is provided, and changes - if any - are indicated. (SID_1) 